\title{
La significación del liderazgo socioreligioso en un contexto de cambios: el Cardenal Raúl Silva Henríquez
}

\author{
Justino Gómez de Benito ${ }^{1}$
}

Fecha de recepción: 10 de septiembre de 2014

Fecha de aprobación: 15 de octubre de 2014

\begin{abstract}
Generalmente en sociología, cuando se hace análisis de los procesos de mutación sociocultural que se han experimentado en las últimas décadas, se coloca a la religión como variable dependiente, en tanto recibe los impactos de dichas transformaciones. Al investigar la figura del Cardenal Silva Henríquez, su significación y su actuar en los diversos contextos sociopolíticos que experimentó el país, aparece un estilo de liderazgo que tiene como origen "un modo religioso de conocer" y un estilo de actuación que marcan y pueden llegar a caracterizar su tiempo como "la época del Cardenal". Al captar los rasgos de su estilo de liderazgo, aparece con nitidez uno de sus principales indicadores: ser un hombre de acción estratégica. Evidentemente, esto implica tener enemigos, enfrentarse a adversarios y, en nuestros términos, tomar partido en procesos conflictivos en los que hay importantes intereses en juego. Él lideró un proceso de renovación de la Iglesia que fue mucho más que una simple adaptación, como reacción a exigencias de nuevos contextos socioculturales.
\end{abstract}

Palabras clave: religión, liderazgo socio-religioso, época de cambios, renovación eclesial

\section{The significance of socio-religious leadership in a context of changes: Cardinal Raúl Silva Henríquez}

\begin{abstract}
Usually in sociology when analyzing processes of cultural mutation experienced in recent decades, religion is placed as a dependent variable since it
\end{abstract}

\footnotetext{
Sociólogo, Doctor en Sociología, Universidad Católica de Lovaina, Bélgica. Académico Universidad Católica Silva Henríquez. jgomez@ucsh.cl

El presente artículo es parte de un trabajo de investigación que el autor viene realizando sobre la trayectoria de la Iglesia chilena en las últimas décadas. Un adelanto relativo al Cardenal Silva Henríquez y su figura, fue publicado en la Revista Mensaje en mayo de 2014. Sin embargo, el presente artículo se sitúa en un segundo momento del trabajo, en el que se ofrece una perspectiva y un análisis situados en el campo propiamente sociológico.
} 
La significación del liderazgo socioreligioso en un contexto de cambios: el Cardenal Raúl Silva Henríquez

- Gómez de Benito

receives the impacts of these changes. When researching the leading figure of Cardinal Silva Henriquez, his significance and actions in different sociopolitical contexts experienced by the country, we find a leadership style that has its origin in «a religious way of knowing» and an acting style that may mark and characterize his time as «the age of the Cardinal». When studying the features of his leadershipstyle, one of the main indicatorsappears clearly: a man of strategic action. This obviously means having enemies and adversaries and - in our terms - taking sides for contentious proceedings with important interests involved. He led a renewal process in the Church that was much more than a simple adaptation, in response to demands for new cultural contexts.

Keywords: religion, socio-religious leadership, time of changes, church renewal

\title{
O significado sócio-religioso da liderança no contexto de mudanças: o Cardeal Raúl Silva Henríquez
}

\begin{abstract}
Resumo
Geralmente em sociologia, quando se fazem análises dos processos de mutação sociocultural que tem sido experimentada nas últimas décadas, coloca-se a religião como variável dependente, no entanto que recebe os impactos de ditas transformações. Ao pesquisara figura do Cardeal Silva Henríquez, o seu significado e seu agirem diferentes contextos sócio-políticos que experimentou o país, aparece um estilo de liderança que tem como origem "uma forma religiosa de conhecer" e um estilo de atuação que marcam e podem chegar a caracterizar o seu tempo como "a época do Cardeal". Ao compreender as características de seu estilo de liderança, aparece claramente um dos seus principais indicadores: ser um homem de ação estratégica. Evidentemente, isto implica ter inimigos, se enfrentar com adversários e em nossos termos, tomar partido em processos conflitivos nos que há interesses importantes em jogo. Ele liderou um processo de renovação da Igreja que foi muito mais que uma simples adaptação, em resposta a demandas dos novos contextos socioculturais.
\end{abstract}

Palavras-chave: religião, liderança sócio religiosa, época de mudança, renovação eclesial.

\section{Introducción}

Generalmente en sociología, cuando se hace análisis de los procesos de mutación sociocultural que se han experimentado en las últimas décadas, se coloca a la religión como variable dependiente, en tanto recibe los impactos de dichas transformaciones. Esto es más patente cuando se aborda el problema desde la pers- 
pectiva de la secularización. Hablar de la religión como variable dependiente es hablar de una variable impactada o influida por otras muchas, especialmente por los profundos y rápidos cambios económicos, políticos y culturales de los procesos de modernización y desarrollo asociados al progreso de los siglos XX y XXI.

Centrándonos en el contexto de la sociedad chilena en los últimos treinta años, la Iglesia Católica en tanto institución, aunque sin constituir un bloque homogéneo, ha sido uno de sus principales actores sociales, desempeñando, según el momento histórico, funciones que han variado desde constituirse en conciencia impulsora y legitimadora del cambio social y estructural hasta un papel de deslegitimación del sistema imperante, pasando por posturas de ambigüedad y contradicción, de cara a los diversos proyectos de cambio impulsados por quienes, democrática o dictatorialmente, han ejercido el poder.

Al investigar la figura del Cardenal Silva Henríquez, su significación y su actuar en los diversos contextos sociopolíticos que experimentó el país, aparece un estilo de liderazgo que tiene como origen "un modo religioso de conocer" y un estilo de actuación que marcan y pueden llegar a caracterizar su tiempo como "la época del Cardenal". Nos encontramos con una figura que no recibe pasivamente el impacto de los cambios impulsados por otros con mayor autoridad o se adapta a los cambios del sistema o del entorno. Con don Raúl el análisis va en la otra dirección. Es él quien impacta en el contexto de cambios. Él toma la iniciativa y el liderazgo de los cambios.

Él es protagonista de los procesos de cambio, primero en su propio campo socio-religioso y eclesial. Pero su proyección incluye el campo de lo sociopolítico. Conocedor de su contexto sociocultural, político y religioso, don Raúl destaca como una figura de líder que supo actuar con creatividad, oportunidad y decisión en circunstancias en que tomar decisiones de cambio suponía riesgos, profetismo y muchas incomprensiones. Al estudiar la 
figura del Cardenal Silva y captar los rasgos de su estilo de liderazgo, aparece con nitidez uno de sus principales indicadores: ser un hombre de acción estratégica. Evidentemente, esto implica tener enemigos, enfrentarse a adversarios y, en nuestros términos, tomar partido en procesos conflictivos con importantes intereses en juego.

El liderazgo carismático se vincula con el estratégico cuando se ejerce con signos y gestos oportunos, comprensibles y de alta significación para quienes lo reconocen y depositan su confianza en él. Don Raúl tuvo la palabra y la acción oportunas en cada uno de los momentos que vivió el país. Fue un hombre de su época, una época de cambios y de tensiones profundas, producidos por los radicales, contradictorios e incluso excluyentes proyectos de transformación que se promovieron o se impusieron en el país.

La primera década de su conducción fue también una época de renovación eclesial. La presencia y participación de don Raúl en el Concilio Vaticano II fue de un notable liderazgo, junto a Mons. Manuel Larraín, don Helder Cámara y otros representantes de la Iglesia latinoamericana. La responsabilidad y decisión con que impulsó el proceso de renovación conciliar en la diócesis de Santiago, a través de la Gran Misión y el Sínodo, no tenía otro propósito que reimpulsar la misión de la Iglesia en la sociedad chilena y sus procesos de cambio. Está claro, a través de su biografía, que no entendió su misión al margen de su sociedad y que era pastor más allá del cerco de su Iglesia. Era pastor para todos quienes quisieran escribir la Historia de Chile. Era pastor con un estilo marcado por la lectura y el discernimiento permanente de la realidad y por su capacidad de respuesta oportuna.

\section{Un contexto de cambio en la iglesia: el Concilio Vaticano II propone un nuevo estilo de ser iglesia}

El Concilio Vaticano II constituye el proceso de adaptación global de la Iglesia al contexto de la nueva civilización industrial y tecnológica, tipificada culturalmente como "la mo- 
dernidad". El nuevo contexto cultural, los nuevos valores y las nuevas maneras de representarse la naturaleza, las relaciones sociales y la existencia misma del hombre, se constituían en un fuerte desafío para la Iglesia. Pero no solo en lo relativo a sus formas de organización, sino sobre todo a su producción de sentido, sus creencias y sus formas de institucionalización. La síntesis medieval entre Iglesia y sociedad llevaba ya varios siglos siendo cuestionada. Por esta razón, interesa establecer la distinción entre los modelos simbólicos o culturales que caracterizan y fundamentan el comportamiento, tanto de aquellos grupos de cristianos aferrados a una representación de la Iglesia de tipo preconciliar, como de quienes intentan renovar la institución Iglesia desde un enfoque de Iglesia postconciliar (Parker, 1985).

El modelo cultural cristiano tradicional preconciliar, generalmente relacionado con una cultura preindustrial y agraria, está caracterizado por los conceptos que Touraine denomina "conciencia sumisa y constituyente". Esta imagen, que da sentido al individuo y a su representación del mundo, cumple también la función de estabilización de la sociedad, además de ofrecer seguridad. La representación de los personajes religiosos son más una especie de figuras divinas que humanas. Ello implica que el rol mediador entre humanidad y divinidad lo asume la Iglesia. Su estructura de autoridad se legitima en su monopolización de la mediación de la salvación y del poder religioso (Hiernaux, 1977).

La Constitución Conciliar sobre la Iglesia en el mundo moderno dio vuelta la antigua visión del mundo, al presentarlo como una realidad al servicio de las personas, las sociedades y su desarro1lo. Este es el fundamento del modelo de cristiano postconciliar. Además, el saber teológico se construye con la lectura de lo social, hecha bajo una óptica científica. Ello implica una valoración práctica y una utilización de las ciencias sociales como instrumento de análisis de la sociedad y sus instituciones, la economía, la política, la cultura, la religión. La óptica mediante la cual se interpreta el mandamiento evangélico del amor conlleva el compromiso de los cristianos por la liberación de toda forma de opresión y por la construcción de 
un mundo a partir de la justicia y la fraternidad. En la Iglesia latinoamericana este modelo se legitima por la autoridad jerárquica en Medellín, en 1968, y años después, en la Conferencia de Obispos de Puebla.

En nuestro análisis, situaremos al Cardenal Silva Henríquez, junto a un conjunto de obispos de la época, como líder protagónico de este movimiento de renovación conciliar.

\section{Don Raúl: su mirada y su acción de pastor en una Iglesia en cambio}

Es evidente que el Cardenal Silva Henríquez, como protagonista de su Iglesia y de su tiempo, hizo su aporte en la construcción de este estilo de ser Iglesia latinoamericana, mirando, juzgando y actuando en su contexto. Pero este estilo de ser pastor y de ser Iglesia se relaciona con la producción de conocimiento, de un conocimiento significativo que orienta y da sentido a la acción.

El capital de autoridad religiosa que puede tener la Iglesia, y en este caso su autoridad, el Cardenal, como indica Bourdieu, "depende de la fuerza material o simbólica de los grupos o clases que puede movilizar al ofrecerles bienes y servicios capaces de satisfacer sus intereses religiosos, de la naturaleza de estos bienes y de estos servicios (...), de la posición de la instancia productora en la estructura del campo religioso, del capital de autoridad religiosa que ella dispone" (Bourdieu, 1971, p. 23).

En lenguaje de Max Weber, el Cardenal podría ser considerado un profeta, en tanto actor religioso caracterizado por un carisma personal que le lleva a ejercer su rol de manera autónoma de la institución religiosa. Es decir, su palabra y su acción no están mediadas por el hecho de tener que guardar coherencia con una tradición sagrada o ser pagado por una institución. El profeta propaga sus ideas por el valor que ellas tienen, no por la retribución que obtenga del hecho de propagar. El estilo profético del Cardenal 
supone lo que yo denomino "un modo pastoral de conocer", que supone una epistemología pastoral, cuyo fundamento y sentido es la identidad y la mirada del pastor: su estilo y su actitud. Su manera de posicionarse en el mundo.

Al observar atentamente la tradición profética, es posible percibir que el método utilizado tiene como punto de partida la realidad y las personas en ella. Es fundamentalmente inductivo y situado en la cultura de su pueblo. El caminar de los profetas por su tierra está lleno de gestos, mediante los cuales se sirven de sus sentidos: miran, gustan, tocan, hablan, sienten, comen, huelen, se acercan, comparten, gritan, se desalientan, se recuperan, etc.

Este modo pastoral de mirar, para saber cómo es y cómo está su pueblo, es fácilmente reconocible en la vida de don Raúl. Se trata no solo de un modo pastoral de conocer, sino de ser. Es un estilo no cortesano ni palaciego, propio de algunas épocas de la historia, o guerrero y conquistador, como en otras, o incluso burócrata o gerencial, propio de las instituciones modernas. Se trata de un modo de ser pastor que capta las condiciones de vida de su pueblo y comprende su realidad y sus esperanzas. Estos lenguajes y signos de la vida del Cardenal son los que me propongo mostrar y descifrar "sin ser sabio competente".

Desde este propósito, he querido destacar algunos ejemplos, sin ser exhaustivo. El Cardenal Silva Henríquez supo tejer su biografía en la historia del país, involucrándose en la vida de las personas y en los procesos de su pueblo, pero involucrando también a su Iglesia de Santiago. Sin duda, el Cardenal hizo historia. Por eso se insiste en hablar de "la época del Cardenal". Esa es la impronta que los grandes personajes de la historia dejan en ella.

La década de los años sesenta encuentra a la Iglesia chilena ya sensibilizada y activa frente a los problemas sociales, distante de la aristocracia terrateniente y con un significativo pluralismo político entre los católicos. La necesidad de una reforma agraria, el derecho a la sindicalización del campesinado y otros aspectos problemáticos de la conflictiva realidad del país eran temas de debate abierto. 
Desde los años 30 habían venido sucediéndose en la Iglesia chilena un conjunto de "profetas" que, además de sensibilizar a los cristianos sobre los problemas sociales derivados de la miseria y de la marginación social, habían promovido entre la juventud la difusión y el estudio de las encíclicas sociales, defendiendo la tesis de que también en Chile debían aplicarse, en contra de la aristocracia y del sector más tradicional del clero, que sostenían la inoportunidad de dicho tipo de magisterio pontificio para este país. En el contexto político nacional, esto significó el apoyo y la legitimación de la Democracia Cristiana (DC), como partido político conformado mayoritariamente por católicos, y el alejamiento de la jerarquía de los sectores de dominio del Partido Conservador.

\section{El problema habitacional como "rasgo dramático de Santiago"}

El crecimiento de la ciudad, el aumento de población, los fenómenos migratorios del campo, etc., fueron realidades que marcaron los primeros años de la década de los sesenta. Desde sus años como director de Caritas, el Cardenal tuvo una larga experiencia en propuestas de solución frente a los endémicos problemas habitacionales que padecía la ciudad de Santiago. Su mirada sobre la ciudad arrojaba un diagnóstico de urgencia: “Las políticas de gobierno se veían en aprietos para atender esa necesidad (...) que resultaba impostergable. Centenares de familias se hacinaban en lugares inauditos, con increíbles problemas sanitarios y alimenticios (...); parecía que un grupo de chilenos tenía condición subhumana. Nadie se preocupaba por su desgracia. Nadie tenía recursos para sacarlos de la tragedia" (Cavallo A., 1994, T I, p. 147).

En la búsqueda de soluciones habitacionales, el pastor se arriesga a llegar a los límites de la legalidad. Don Raúl llegó a dar su parecer afirmativo a los pobladores que le consultaron sobre la alternativa de tomarse unos terrenos del Estado en la zona sur de 
Santiago. Junto a la solución habitacional, se preocupó también de su seguridad:“¿Cómo iba a seguir toda esa gente expuesta a una condición tan infame? ‘Bueno - dije-. ¡Háganlo!, es cosa suya. Yo me voy a preocupar de las casas. Y trataré de conseguir que no los echen'"' (Cavallo A., 1994, T I, p. 149).

\section{"La Reforma Agraria fue la gran esperanza de los años 60"}

La aparición en 1962 de las Cartas Pastorales: "La Iglesia y el problema del campesinado chileno" y "El deber social y político en la hora presente", significó el impacto de la palabra fuerte y unánime de una jerarquía que rompe con las formas tradicionales de pronunciarse frente a la opinión pública y al debate político y social. En estos documentos, los obispos asumen la opción por el "desarrollo" y plantean la incapacidad del sistema político-económico capitalista para hacer viable, sin conflictos, la participación social y política de los marginados. Las palabras de la jerarquía refrendaban además una decisión que se hacía realidad por aquellos días.

El Cardenal Silva y Mons. Larraín iniciaban un proceso de reforma agraria en las antiguas propiedades agrícolas de sus diócesis y que fueron luego entregadas a los propios campesinos. Este gesto, que se adelanta a los procesos de reforma agraria iniciados años más tarde bajo la conducción de políticos cristianos progresistas -además de reflejar la posición de los dos obispos más influyentes de la Conferencia Episcopal-, se constituye en una abierta ruptura y enfrentamiento con las posiciones políticas y los intereses de clase de la burguesía tradicional terrateniente, heredera y defensora de un pasado casi de tipo semifeudal.

"La reforma agraria fue la gran esperanza de los años 60". Esta es la opinión taxativa del propio Cardenal en sus memorias. Esta expresión del pastor contiene y se fundamenta en una experiencia y una relación cercana con la realidad campesina: “La legislación social era infringida en porcentajes demasiado altos, desde la falta de contratos de trabajo hasta las malas condicio- 
nes de vivienda, salubridad y alimentación; la alta mortalidad infantil del país se radicaba principalmente en el campo; la difícil situación del pequeño agricultor, debido a los desequilibrios en los precios y la falta de apoyo técnico y crediticio; la depresión general del campesinado en materia de sueldos, estabilidad, trato justo y descansos; y en fin, los índices crecientes de emigración de la población rural a las ciudades en busca de mejores horizontes" (Cavallo A., 1994, T I, p. 243).

En marzo de 1962 el Cardenal, en audiencia privada con el Papa Juan XXIII, le comparte su voluntad de implementar la reforma agraria y detalla en sus Memorias que el Papa, después de pensar un momento, le dijo: “¡Hágalo, yo le respaldo!” Pero, ¿por qué lo hizo?: “...porque la Iglesia debía ser leal y sincera consigo misma y con todos los chilenos. (...) Creíamos que nuestro ejemplo contribuiría a crear un espíritu de reforma y de transformación de nuestros campos, cambiando sistemas de dependencia y opresión por nuevas formas de vida, donde el trabajador campesino se sintiese responsable, respetado y digno (...). Un sistema de más justa división de tierras, demasiado extensas o mal explotadas, que beneficiase al trabajador $y$, a largo plazo, a todo el país (Cavallo A., 1994, T I, pp. 79-80).

Pero no les dejó solos en la travesía hacia el nuevo orden. Además de entregar los títulos de dominio a los campesinos, se preocupó de que tuvieran apoyo técnico para el proceso:"He venido hasta aquí a verlos personalmente para escuchar sus impresiones del trabajo que estamos realizando. No quiero que guarden nada bajo el poncho. Todos sus problemas deben tratarlos también con estos caballeros que me acompañan, que son de INPROA y que trabajan precisamente en esto: asesorarlos a Uds." (Timmerman, 2008, p. 85).

Notable fue la confianza en los campesinos. Ese fue su estilo. Lo testimonia uno de ellos: "Nos reunimos bajo los aromos de las casas patronales en círculo y el Cardenal al centro dando a conocer todas sus inquietudes (...) Él confiaba en que nosotros íbamos 
a salir adelante. Pero que tendríamos críticas y problemas. Él nos pedía que siguiéramos con fe, en bien de la familia. Que nos organizáramos en una Cooperativa para que estuviéramos unidos y pudiésemos buscar los créditos para sus afiliados (Aliaga, 2001).

Algunos años después, en el contexto del gobierno militar, el Cardenal expresaba su preocupación por el futuro de los que habían sido beneficiarios de la reforma agraria. "Hay que hacer algo", pasó a ser una de las frases típicas del Cardenal. Este sentido práctico y resolutivo le llevó incluso hasta a escribir a los bancos acreedores para interceder por los campesinos adeudados.

\section{"La crisis de la Universidad Católica fue uno de los capítulos más difíciles de mi vida"}

El Cardenal era consciente de que en esos años la crisis de las universidades católicas no era algo aislado o único en Chile. El CELAM comisionó a su Departamento de Educación para estudiar el asunto a comienzos de 1967. El diagnóstico que compartía sobre la situación de las universidades católicas daba cuenta de “...que la falta de acción de estas universidades en el campo social podía ser un grave síntoma de enajenación; que en ellas debía ejercerse una crítica activa contra la falsedad social, política e histórica; y que debían constituir un aporte al desarrollo" (Aliaga, 2001, p. 89).

Lo más grave, a juicio del Cardenal, era que la Universidad Católica (UC) se estaba convirtiendo en otra iglesia al margen de los procesos de renovación conciliar. Así lo denuncia en sus Memorias:"...numerosos académicos se quejaban de que eran excluidos de la U.C.; acusaban a sus directivos de convertir las aulas en un reducto liberal-conservador, con un enfoque ideológico excluyente (...). Para mí comenzó a ser evidente que la U.C. estaba convirtiéndose en una diócesis dentro de la diócesis. Los planteamientos de los obispos no tenían cabida en ella y los del arzobispo tampoco. Peor aún, los estudiantes no eran escuchados 
y se quejaban de que la doctrina social de la Iglesia no tenía reflejo en su formación..." (Cavallo, 1994, T. II, p. 92).

El análisis del Cardenal fue que los estudiantes no tenían confianza en que el rector, Mons. Silva Santiago, iniciara las reformas, así que plantearon un plebiscito bajo el lema "Deseamos un cambio en la alta autoridad de la Universidad", que ganó por muy amplia mayoría, pero fue rechazado por el Consejo Superior. Las múltiples gestiones de don Raúl con el Vaticano, con el gobierno y la Cancillería, con los propios estudiantes, con las autoridades de la UC y con el Comité Permanente del Episcopado, en orden a mediar y buscar soluciones al problema, fueron dando resultados positivos. Pese a sus reservas, don Alfredo Silva Santiago accedió al nombramiento de Fernando Castillo Velasco como rector. Sin duda, el Cardenal escuchaba a los jóvenes, tenía prestigio entre ellos y esta confianza que depositaban en él, a diferencia de la desconfianza que mostraban frente a la gestión del rector Silva Santiago, fue haciendo posible la solución de la crisis. Pero el conflicto no terminó, porque los ataques desde dentro y desde fuera de la Universidad y de la Iglesia misma se sucedieron: "En los diarios y publicaciones del sector conservador comenzaron inmediatamente los ataques en mi contra, con una tergiversación abierta de los hechos. Una de las noches pintarrajearon mi casa, escribiendo que no era un verdadero cardenal y calificándome de traidor y filocomunista" (Cavallo, 1994, T. II, p. 105).

El Mercurio denuncia el movimiento como "un plan elaborado y divulgado por los comunistas". Esta información falsa impulsa a los estudiantes a desplegar un enorme lienzo en la fachada de la Casa Central de la UC, que no será olvidado hasta hoy: “¡Chilenos: El Mercurio miente!".

La evaluación final del Cardenal ratifica la necesidad de haberse empeñado en un proceso de reforma: "A pesar de todo, la reforma fue uno de los procesos más interesantes que se haya llevado a cabo en América Latina (...). Por mi parte, creía entonces 
y lo sigo creyendo ahora, que a fines del 67 , se abrió uno de los mejores períodos que ha tenido la Universidad (Cavallo, 1994, T. II, p. 109).

\section{El Cardenal es de los que sufren}

El 16 de septiembre de 1973, días después del golpe militar en Chile, expresó públicamente su actitud de pastor de todos, pero especialmente de los que más sufren. Uno de sus primeros gestos públicos fue visitar a los presos del Estadio Nacional. Así lo narra personalmente en sus Memorias. Sus palabras resonaron en las graderías del Estadio. Y su gesto sembró la confianza entre los presos:

Centenares de personas estaban detenidas sin proceso y se hablaba de maltratos, interrogatorios violentos y hasta de fusilamientos. En vista de esto decidí ir a visitar el recinto (...). Vi de inmediato que muchos de ellos me recibían como si fuese su única esperanza sobre la tierra, con ansiedad, hasta con desesperación (...). En un momento me sentí mal y no pude contener las lágrimas" (...).'Quizás Uds. no me conocen -dije-. Me llamo Raúl Silva Henríquez; soy el cardenal de la Iglesia Católica. Soy el representante de una Iglesia que es servidora de todos y especialmente de los que están sufriendo. Quiero servirlos y, como el Señor, no pregunto quiénes son ni cuáles son sus creencias o posiciones políticas. Me pongo a disposición de los detenidos. Cualquier cosa háganmela saber' (Cavallo, 1994, T. III, pp. 293-294).

Don Raúl se hizo cargo de apoyar y canalizar la iniciativa de esconder y asilar perseguidos. La defensa de los derechos humanos se transformó "en la tarea caracterizadora de la Iglesia durante las décadas siguientes". Primero se organizó el Comité Nacional para ayuda a refugiados. A los tres meses se constituyó, en colaboración con otras iglesias del país, el Comité de Cooperación para la Paz en Chile, organismo que tuvo como misión 
prestar asistencia legal y social a las víctimas de las gravísimas violaciones a los derechos humanos.

Más adelante, en 1976, se creó la Vicaría de la Solidaridad, institución que vino a reemplazar al Comité y que asumió la continuación de su tarea. La Vicaría de la Solidaridad operó durante todo el régimen militar y concluyó sus actividades el 31 de diciembre de 1992. Esta Vicaría nacía sobre las durísimas experiencias del Comité Pro Paz, en el edificio de Plaza de Armas 444, recinto vecino a la Catedral: "más oficial, imposible", dice el Cardenal en sus memorias.

“¿Por qué se metió en Pro Paz? (...) ¿Por qué hizo la Vicaría? (...) Él responde: "La Vicaría nació de una larga y sufrida reflexión en torno a lo que vivíamos día tras día (...) Nos dimos cuenta (...) de que no eran sólo nuestra voluntad ni nuestras capacidades institucionales lo que nos movía en esa dirección: era la doctrina cristiana, su llamado imperioso para ser consecuentes..." (Cavallo, T. III, pp. 87-88).

Junto a los obispos, el Cardenal ve al pueblo chileno "en manos de los asaltantes", en la cruz, entre la vida y la muerte. Se percibe a Chile como un espacio de muerte: de terrorismo de Estado, de terroristas, del sistema político y económico, con detenciones arbitrarias, exilio, asesinatos políticos, secuestros, etc. (Gómez, 1995, pp. 268-70).

Como pastor, observa la lucha entre la vida y la muerte. Es testigo cotidiano del drama de su pueblo: toma posición decidida. Son un pastor y una iglesia testigos del drama de su pueblo. Para ello se sirve de profesionales de las ciencias sociales que, en sus vicarías y proyectos, colaboran: abogados, sociólogos, trabajadores sociales, antropólogos, psicólogos, economistas, profesores, médicos y enfermeras, etc.

Los familiares de los detenidos desaparecidos siempre encontraron en él una palabra y un gesto de apoyo a su causa, muchas veces incomprendida en la sociedad, pero también en algunos sectores de la Iglesia. Sola Sierra lo recuerda: “Cómo no recordar 
su figura, mitigando el dolor de quienes eran torturados de norte a sur del país, o de los que llegaron al Comité para la Paz (...) para recibir las denuncias de los atropellos a los derechos humanos que se cometían en nuestro país. Su figura para mí es la de un padre, que cuando sus hijos sufrieron en carne propia el terror que se les impregnó en la piel ante la barbarie que se desató después del 11 de septiembre de 1973, con su brazo fraterno consoló el sufrimiento del alma de los familiares de víctimas, de un Chile que se sumió en el dolor y en el luto..." (Gómez, 1995, p. 203).

Viviana Díaz, otra de las dirigentes de esta agrupación, habla de lo que significaba la Vicaría para ellas: "La Vicaría para mí y para todos los familiares de las víctimas, era como el oasis que teníamos dentro de todo lo que pasaba en Chile; bastaba que uno cruzara la Plaza de Armas y subiera las escaleras al segundo piso para sentirse en otro lugar; en la Vicaría uno se sentía tranquila y sabía que nada le iba a pasar (...), claro que cuando a las seis de la tarde había que irse, ahí una nunca sabía si iba a llegar a la casa o no" (FCRSH, 2007, p. 164).

\section{La Vicaría Pastoral Obrera: cercanía y apoyo a las organizaciones y luchas de los trabajadores}

Ya en la década de los sesenta, el Cardenal creó la Fundación Cardjin, para prestar asesoría a los líderes laborales, desarrollando programas de formación entre el sindicalismo cristiano. Junto a esta fundación se creó el Centro de Estudios Laborales. Al respecto, comenta el Cardenal: "Estas entidades ayudaron, sin duda, a cambiar la mentalidad de la Iglesia para hacerse cargo de estos problemas. En la Iglesia tradicional, los conflictos del trabajo eran algo ajeno y distante, que a menudo se reprobaba sin conocer. Los obreros veían a la Iglesia como una aliada de los patrones; y éstos reaccionaban como que así fuera por mandato divino" (Cavallo, 1994, T. III, p. 107).

También en la misma década había promovido el desarrollo del Movimiento Obrero de Acción Católica (MOAC), como un 
espacio de presencia significativa en el mundo del trabajo. Fue el caso de su actuar en la huelga de la empresa Yarur, apoyando la olla común de los huelguistas, por lo que fue muy criticado desde sectores tradicionales de la Iglesia. Sin embargo, el Cardenal los increpó: "Y qué quieren que hagamos? ¿Que les dejemos solos? ¿Que les castiguemos por hacer una huelga? ¿Que les abandonemos en otras manos que sí están dispuestos a apoyarlos? (Cavallo, 1994, T. III, p. 107).

La Vicaría surge de una visión: “En los años anteriores habíamos visto aumentar casi geométricamente la cantidad de trabajadores que se acercaban a nuestros sacerdotes y a la Vicaría de Solidaridad para pedir ayuda y consejo en sus problemas laborales. Por supuesto, en una mayoría de los casos, se trataba de gente que había perdido el empleo y quería defensa" (Cavallo, 1994, T. III, p. 104).

La Vicaría de Pastoral Obrera nace desde la profunda convicción del Cardenal sobre el diagnóstico de la relación entre la Iglesia y el mundo del trabajo: "En primer lugar no teníamos a los obreros. Ellos no sentían que la Iglesia los acompañara en sus aspiraciones (...).En segundo lugar la experiencia de formar gente, con todos sus buenos resultados, se mostraba insuficiente (...) En tercer lugar, bajo las condiciones impuestas por el régimen militar, a menudo tan duras para los trabajadores, la Iglesia tenía la oportunidad de constituirse en un lugar de encuentro, un hogar" (Cavallo, 1994, T. III, p. 107).

Para proteger a los trabajadores de las autoridades militares, en las actividades que organizaba la Vicaría, el Cardenal ordenó imprimir un documento con membrete del Arzobispado en el que se señalaba que él autorizaba estos encuentros, con el objetivo pastoral de difundir la enseñanza social de la Iglesia. ¿No tuvo problemas el Cardenal a raíz de esto?, le preguntaron al P. Alfonso Baeza en una entrevista en la revista Mensaje: "Sí, recuerdo que una vez lo llamaron desde altas esferas del gobierno para advertirle que se habían enterado de que él estaba facilitando 
locales e instalaciones de la Iglesia para reuniones sindicales y que en ellas se reunían dirigentes sindicales y trabajadores, en su mayoría opositores al gobierno. El Cardenal les respondió muy serenamente: 'mire, nosotros ahí enseñamos la Doctrina Social de la Iglesia, y los trabajadores, bueno (...) lo que ellos hagan en el recreo $(. .$.$) es cosa de ellos'"'2.$

Uno de los frutos más significativos del apoyo de la Vicaría a los trabajadores fue la reconstitución del movimiento sindical. En 1978 se formó la Coordinadora Nacional Sindical y funcionó en el garaje de la misma casa de la Vicaría, lugar donde, en 1984, sesionó el Comando Nacional de Trabajadores.

Pero una de las más importantes intervenciones del cardenal Silva Henríquez fue su esfuerzo por establecer condiciones de paz con Argentina. El litigio fronterizo por el Canal Beagle se resolvió mediante un fallo arbitral pronunciado en 1977, pero el gobierno argentino le desconoció validez y ambos países comenzaron sus preparativos bélicos. El cardenal Silva primero solicitó personalmente al Papa Juan Pablo II la mediación del conflicto y, posteriormente, realizó grandes esfuerzos para establecer las condiciones de diálogo.

\section{Conclusión: los riesgos y la legitimación de un líder}

Sería interminable, pero no menos interesante, continuar el análisis de cada uno de los gestos, palabras y acciones del Cardenal Silva en los que expresa este estilo de pastor situado y comprometido con su momento y su contexto histórico. Se trata de un estilo de pastor coherente, fundamentado en una estrecha y firme relación entre su pensamiento y su acción, presente en el liderazgo de los procesos de cambio. Pero quedaría inconcluso el análisis si no se tomaran en cuenta "los enemigos del Cardenal".

Revista Mensaje, 624, p. 21. 
Es una tarea que continúa. Como todo liderazgo, se vio enfrentado a adversarios, enemigos, colaboradores y resistencias.

Haciendo una primera clasificación sobre el tema se podría plantear el siguiente cuadro:

\begin{tabular}{|c|c|}
\hline En el campo eclesial & En el campo político \\
\hline Adversarios & Adversarios \\
\hline Católicos conservadores-terratenientes & Burguesía - Empresariado \\
\hline $\begin{array}{l}\text { Cabildo metropolitano y sacerdotes } \\
\text { conservadores }\end{array}$ & \multirow{3}{*}{$\begin{array}{l}\text { Propietarios terratenientes y orga- } \\
\text { nizaciones Nacional de Agricul- } \\
\text { tura (SNA), La Confederación de } \\
\text { Sindicatos de Empleadores Agrí- } \\
\text { colas (CEA), y el Consorcio de la } \\
\text { Agricultura del Sur (CAS). }\end{array}$} \\
\hline \multirow[t]{4}{*}{ Opus Dei, Grupos del P. Karadima } & \\
\hline & \\
\hline & $\begin{array}{l}\text { Políticos de derecha y también de } \\
\text { izquierda }\end{array}$ \\
\hline & El Mercurio \\
\hline Enemigos & Enemigos \\
\hline Jaime Guzmán & UDI y gremialistas \\
\hline El Nuncio Angelo Sodano & Gobierno militar: Pinochet \\
\hline
\end{tabular}

El Cardenal identificó a sus enemigos y adversarios. Al día siguiente de su intervención en el Concilio Vaticano II, comenta el hecho en sus Memorias:

El Mercurio tituló: 'Cardenal Raúl Silva Henríquez afirmó en el Concilio que es excesiva la devoción mariana'. (...) Esta tergiversación hacía recaer sobre mí la responsabilidad de 'enemigo' de la Virgen, como nos querían presentar nuestros contradictores (...) El grupo conservador utilizaba distintas formas para manifestar su oposición a mi gestión pastoral (...). A los pocos días el Cabildo Metropolitano (...) rechazó la entrega de los fundos del Arzobispado (...). Apenas recibida la noticia de esta decisión adversa (...) me llamaron desde el Santo Oficio para informarme que había llegado hasta ellos una acusación firmada por varios eclesiásticos y un número mayor de feligreses laicos. (Cavallo, 1994, T. I, pp. 25-26). 
Pero más allá de los enemigos, cuyas estrategias contra el líder religioso no hacen otra cosa que fortalecer su condición y su legitimación frente a la Iglesia de Santiago, sus comunidades y parroquias, pero también frente a quienes encontraron en él la seducción del atrevido, del que corre riesgos por los más débiles y los que no tienen ni defensa ni voz, encontramos un conjunto de testimonios de valoración de su liderazgo. Don Bernardino Piñera, varias veces su brazo derecho en la conducción de la Conferencia Episcopal, sintetiza el sentir de quienes lo admiraron en el ejercicio de la autoridad:

Siempre vi al Cardenal Silva Henríquez como un boxeador de peso pesado a quien le gusta el ring (...). El Cardenal a veces pegaba fuerte. No era bueno para esquivar golpes, pero he conocido pocos hombres más pacientes para aguantar los golpes que no podía esquivar, para absorber castigo, como dicen los comentaristas de box (...) Era un hombre austero, un hombre de deber, un luchador. Un hombre que fue muy incomprendido y muy golpeado. Su acogedora mesa de comedor fue para él un refugio, un descanso en las horas amargas (...). El Cardenal era fuerte. Tenía gran capacidad de liderazgo. Sabía elegir a sus colaboradores, darles su confianza y ganarse su lealtad y su cariño. Sabía decir lo que había que decir sin rodeos, a veces con vehemencia, con pasión. Pero era prudente ${ }^{3}$ :

En el campo político, varios connotados representantes de partidos políticos reconocieron y valoraron su liderazgo.

Carolina Tohá:

Entendió y acogió a los jóvenes de los 60, con su entusiasmo reformista y su vocación por el cambio social. A veces, también peleó con ellos, pero siempre desde la 
legitimación de sus sueños. Defendió como un león el derecho a pensar y a expresarse de los jóvenes de los 70 y de los 80, y buscó protegerlos de la represión y la persecución de esos años. Y, en los 90, ya al final de su vida, cuando se puso de moda decir que los jóvenes "no estaban ni ahí", insistió en la importancia de considerarlos. Para él, el entusiasmo de la juventud era un motor señero de la historia, de todas las historias (...). No puedo dejar de recordar aquí la actitud que tuvo el cardenal con motivo de la muerte de mi padre, José Tohá, En esa ocasión, ofreció oficiar la misa fúnebre en la Catedral de Santiago. Ante esto, recibió un llamado de atención del gobierno exigiéndole que se desistiera porque no correspondía despedir con una misa a un ateo que, además, era suicida, pues esa era la versión oficial de la causa de su muerte. Ante esto, el Cardenal insistió en que haría la misa de todas maneras, y ofrecería la capilla de su propia casa para oficiarla ${ }^{4}$.

Para Andrés Aylwin, abogado que trabajó en la Vicaría de la Solidaridad, el Cardenal es la figura más importante del Chile del siglo XX, pues apareció un hombre como él, fuerte y enérgico, en tiempos en que el odio se instauró como ideología y sistema, llevando a los chilenos a sentirse enemigos entre ellos mismos ${ }^{5}$.

El ex rector de la Universidad de Chile Luis Riveros reconoció también su liderazgo y dijo de él:

El Cardenal no actuó solamente inspirado por su amor por el prójimo, por su espíritu maduro y profundo como pastor de la Iglesia Católica. Lo fue también como un chileno de gran sensibilidad frente a la historia que le

\footnotetext{
4 Homenaje de la Cámara de Diputados en memoria del Cardenal Raúl Silva Henríquez, en el centenario de su nacimiento, en Encuentro, Digital, 5, julio 2007, disponible en http://www.periodicoencuentro.cl/julio2007/html/top2 \_a.html 5 Disponible en http://www.salesianos.cl/2007/Ilustre-Municipalidad-de-LaGranja-inicia-celebracion-del-Centenario-del-nacimiento-del-Cardenal-Silva.html
} 
tocó vivir. Silva Henríquez fue un profundo observador de su tiempo, un analista, una persona que sacó conclusiones de la historia viva y contradictoria del presente siglo (...). Tuvo enemigos, quienes desaprobaron su forma de actuar, su pasión por la justicia, y su empeño por lograr el acuerdo conducente al progreso y la superación de la crisis por etapas de diálogo ${ }^{6}$.

El Cardenal intuía muy bien y muy certeramente lo que el pueblo pensaba y lo que quería. Por eso siempre se produjo una corriente de simpatía muy grande entre las masas y él.

"Usted ha devuelto la credibilidad a la Iglesia", le expresó una autoridad de la Santa Sede al Cardenal. Sus gestos, sus acciones, sus palabras se ganaron la credibilidad.

Nos encontramos hoy, ya en otro siglo, en una crisis de credibilidad y confianza en las instituciones y especialmente en relación con la Iglesia católica. Si hoy las opiniones muestran su bajo nivel de credibilidad entre los chilenos es porque sus gestos y sus lenguajes no conmueven. El desafío será entonces recuperar el sentido original que motivó su constitución, desde una comprensión y discernimiento lúcidos de la cultura, la sociedad y las personas.

Haber analizado palabras y gestos del Cardenal nos ha llevado a recuperar el contexto del Concilio Vaticano II como gran acontecimiento eclesial del siglo XX, en el marco de los cincuenta años de su celebración. Aquella Iglesia amable y cercana, con gestos y lenguajes claros de sus pastores, que supo enjugar las lágrimas de los rostros afligidos en contextos de dictadura, que, aunque tuvo poder, lo puso al servicio de los más débiles y vulnerables, aparece hoy lejana y poco creíble. Los procesos experimentados en la Iglesia de Santiago bajo la conducción de don

Disponible en http://www.uchile.cl/portal/presentacion/historia/luisriveros-cornejo/discursos/6130/homenaje-al-cardenal-raul-silva-henriquez-conmotivo-de-su-natalicio 
Raúl se recuerdan hoy como anhelos por continuar ofreciendo mayores espacios de participación laica, mayor protagonismo de la mujer; por una comprensión de la autoridad más colegiada, que muestre una imagen de Iglesia como comunidad comprometida con las búsquedas de su pueblo. El estilo de don Raúl lideró un proceso de renovación de la Iglesia que fue, más que una simple adaptación, una reacción a exigencias de nuevos contextos socioculturales. Su estilo se asemejó más a la lucidez de muchos hombres y mujeres, fundadores de congregaciones y misioneros que, con decidido liderazgo, supieron descifrar los signos de su tiempo y se adelantaron a interpretar, resolver y dar respuesta a necesidades de su época y de su gente, especialmente de aquellos sectores que más pudieran sufrir por sus condiciones de exclusión. Hoy los temas de la sociedad chilena no son los mismos. Golpean fuertes los gritos del pueblo mapuche; las minorías sexuales exigen poner fin a las discriminaciones. Los nuevos movimientos sociales y sus movilizaciones buscan no solo soluciones técnicas sino horizontes de sentido. Parece entonces oportuno imaginarse cómo abordaría hoy el Cardenal Silva estos nuevos desafíos.

\section{Referencias}

Aliaga, F. (2001). Anuario de la Historia de la Iglesia en Chile. Santiago: Pontificio Seminario Mayor.

Bourdieu, P. (1971). La religion selon Max Weber, in Archives Européennes de Sociologie, XII, pp. 3-21.

Bourdieu, P. (1971) (b). Genése et structure du champ religieux, en Revue Francaise de Sociologie XII, pp. 295-334.

Cavallo, A. (editor) (1994). Memorias del Cardenal Raúl Silva Henríquez. Santiago: Copigraph.

Fundación Cardenal Silva Henríquez (FCRSH).(2007). El amor de Cristo nos urge: 90 años del Cardenal Raúl Silva Henríquez. Santiago: Ed. Despertar.

Fundación Cardenal Silva Henríquez (FCRSH). (2008). La Patria Anhelada. Santiago: EDEBE-UCSH. 
Gómez de Benito, J. (1995). Proyectos de Iglesia y proyectos de sociedad. Santiago: Ed. San Pablo.

Hiernaux, J. P. \& Ganty, A. (1977). Sociologie des groupes chretiens contemporeans. Systémes symboliques, insertion sociale et mobilisation affective. Centre de Recherches Socio-religieuses: Centre de Sociologie Urbaine et Rurale (Section d'Analy seculturelle). Louvain-la-Neuve: Université Catholique de Louvain.

Houtart, F. \& Remy, J. (1969). Eglise et société en mutation. Tours: Mame.

Ortega, M. (1982). El Cardenal nos ha dicho. Santiago: Ed. Salesiana.

Ortega, M. (1999). Así pensaba el Cardenal. Santiago: Ed. San Pablo.

Parker, C. (1985). Religión y clases subalternas urbanas en una sociedad dependiente. Dissertation doctorale, Vol. II, Louvain la Neuve, Université Catholique de Louvain, Faculté des Sciences Economiques, Sociales et Politiques, Département de Sociologie, p. 224.

Rubio, P. (2007). El Cardenal Silva Henríquez frente al movimiento gremial. Progresismo y conservadurismo en la reforma universitaria de la Universidad Católica de Chile, 1967, en Revista Historia y Geografía, 21.

Sapag, R. (editor) (1997). Raúl amigo... Santiago: Ed. Copigraph.

Sapag, R. (2010). Homenaje de los Pastores del Pueblo al Cardenal del Pueblo. Santiago: Ed. Copigraph.

Timmerman, F. (2008). El Cardenal Silva Henríquez y el mundo campesino. Una experiencia de desarrollo y promoción humana. Santiago: Fundación Cardenal Silva Henríquez y UCSH.

Touraine, A. (1969). Sociología de la Acción. Madrid: Ariel, pp. 133-138. 
